\title{
The Therapeutic Role of Ziziphus Extract on Liver Injury Induced by Electromagnetic Waves and Ionizing Radiation as Environmental Pollutants
}

Heba M. Karam ${ }^{1}$, Ola A. Gharib ${ }^{1}$

Received: 21/10/2018

Accepted: 24/12/2018

E.mail:Heba.Karam.Mohmed@gmail.com

\section{KEYWORDS}

\section{Electromagnetic}

Waves, Ionizing

Radiation, Ethanol

Ziziphus Extract,

Heat Shock Protein70,

Environmental

Pollutants.

\section{ABSTRACT}

This study shows to what extent treatment with Ziziphus mauritiana Lam can ameliorate the hazards induced by exposing animals to EMW with a frequency of $950 \mathrm{MHz}$ and 4 Gy single dose of gamma ionizing radiation in serum and liver tissue. Rats were segregated into six groups control, EMW, whole body $\gamma$ - irradiation, EMW followed by $\gamma$ - irradiation and EMW followed by Ziziphus extract then exposed to $\gamma$ - irradiation groups. Irradiation with $4 \mathrm{~Gy} \gamma$ - rays significantly increased the levels of serum Alpha-Fetoprotein (AFP), Alanine Aminotransferase (ALT) and Aspartate Aminotransferase (AST) activities; with substantial reductions in liver glutathione peroxidase (GPx), while lipid peroxides as malondialdehyde (MDA), nitric oxide (NO), Heat Shock Protein 70 (HSP 70), Nuclear Factor $\kappa B$ (NFkB) and tumor suppressor protein (P53) levels significantly increased in liver tissue after EMW or ionizing radiation exposure. However, these effects became marked in all parameters in Group 5 as compared either to Group 3 or 4. Interestingly, among the tested parameters, ziziphus extract showed significant recovery in the previous biochemical parameters. Ziziphus extract is effective antioxidants and could be attenuate oxidative damages caused by electromagnetic and ionizing radiation.

1. Drug Radiation research Department, National Center for Radiation Research and technology, Atomic Energy Authority, Cairo, Egypt. 


\section{INTRODUCTION}

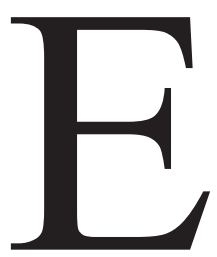

lectromagnetic wave, to which mobile phone belongs to, is a type of nonionizing radiation that emits sufficient energy only for excitation instead of generating charged ions when passing through matters. The potential biological action of mobile phone on human body found to be through the generation of heat (thermal effect) that may lead to a rise in tissue or body temperature and the hazards depend on its ability to permeate human body and absorption characteristic of different tissues. Thermal effects may induce disturbance in cellular function and development (Deepinder et al., 2007). The inflicted tissue injury in humans could take place due to the body's facility to dissipate the excessive heat. Furthermore, exposure to electromagnetic wave emitted from the cell phone caused a production of free radicals and disruption of their metabolism that contribute to formation of oxidative stress (Ghodbane et al., 2013). According to Desai and his colleagues' acute exposure to electromagnetic wave can excite plasma membrane NADH oxidase which can raise the formation of reactive oxygen species (Desai et al., 2009), while chronic exposure to reactive oxygen species (ROS) can lead to phosphorylation of heat shock proteins (HSP) which prevents apoptosis. Inhibition of apoptosis might encourage carcinogenesis by prolonging survival of cells with DNA damage. Moreover, according to Shckorbatov the mechanism of EMW induced chromatin condensation may include the primary effects associated with changes in DNA protein interaction by EMW (Shckorbatov, 2014).

On the other hand, all types of ionizing radiation generate ions contribute to the creation of free radicals; reactive oxygen species and reactive nitrogen species. Excess production of free radicals or reductions in antioxidant level can lead to oxidative stress in target tissues elevation of cytokines levels and other intercellular signals. Intercellular signals encourage production of free radicals and inflammatory mediators by intermediate enzymes such as cyclooxygenase-2 (COX-2), nitric oxide synthase (NOS), NADPH oxidase. Furthermore, some experiments suggested that some cytokines such as IL-1 $\beta$, TNF- $\alpha$, IL-4 may help mitigate radiation toxicity. Owing to the harmful effects of ionizing radiation, applications of an external source of antioxidants can support in coping with this oxidative stress (La Verne, 2000). Therefore, to find out the effective, non- toxic, natural compounds with antioxidant activity has been massive to protect humans against non-ionizing and ionizing radiation induced normal tissue injuries.

The medicinal plants are given more consideration for their efficiency, safety and synergistic effects as illustrated in WHO played a key role in human health care. Ziziphus mauritiana belongs to the family Rhamnaceae (WHO, 1993). The leaf extract found to be helpful in liver diseases, asthma and fever (Morton, 2004). The chemical composition of the plant has been studied and well known by Ikram and Tomlinsim (1976) and Younes et al. (1996). Phytochemical compounds present in the Ziziphus mauritiana leaf extract with possible antioxidant activity are tannins, phenolic compounds and flavonoids. The principle constituent of all-important oil was alpha-terpineol (16.4\%), which inhibits the growth of tumor cells by a mechanism that involves inhibition of the NF- $\kappa$ B pathway (Hassan et al., 2010). While the large percentage of flavonoid content was found in the leaves $(0.66 \%)$; that possess many biochemical properties, merely the best described property is their capability to work as antioxidants. Mechanisms of antioxidant action include (1) destruction of ROS formation either by inhibition of enzymes or by chelating trace elements involved in free radical generation; (2) up-regulation or protection of antioxidant defenses and (3) scavenging ROS (Mishra et al., 2013). According to Dahiru and his colleagues' ethanol extract of Ziziphus mauritiana leaf exhibited hepatoprotective activity against 
carbon tetrachloride $(\mathrm{CCl} 4)$-induced liver damages in rats (Dahiru et al., 2006).

This work was intended to determine the effects of the hazards of EMW in mobile phone range and/ or ionizing radiation as environmental pollutants. The current study was extended to evaluate the efficacy of ethanol extract of Ziziphus mauritiana leaf treatment on rats exposed to electromagnetic waves and gamma rays induced liver oxidative injury.

\section{MATERIALS AND METHODS}

\section{Materials}

The fresh leaves of Ziziphus mauritiana Lam. blongs to the family Rhamnaceae. were collected from the farms of Atomic Energy Authority, Inshas, Egypt. Plant leaves were authenticated by Dr. Noheir Sherif, Assistant professor of Phytocognosy (NCRRT). The plant material was air dried and kept in a firmly closed container till the process of extraction.

All chemicals used in these experiments were purchased from Sigma Chemical Co.

\section{Extract preparation}

The zizphus extract was prepared by soaking $200 \mathrm{~g}$ of dried and powdered leaves in soxhlet extractor for 48 hours at $60 \mathrm{c}$, and then solvent was evaporated to dryness at 50-55 $\mathrm{C}$ using a rotary evaporator. Finally, the lypholization was done (Kil et al., 2009). The extract was stored at $4{ }^{\circ} \mathrm{C}$ till the analysis of different parameters.

\section{Animals and treatments}

\section{Animals}

Male albino rats used in the current study were obtained from animal breeding unit of the national center for radiation research and technology (NCRRT), Nasr City, Egypt. Each animal weigh 120-150 gm with the age of 10 to 12 weeks. Rats were housed under standard conditions of controlled humidity, temperature and light. The animals were allowed free access to water and were fed a standard pellet rat diet. The survey was conducted in conformity with the guidelines lay out by the European Economic Community (EEC) regulations (Revised Directive $86 / 609 /$ EEC) and sanctioned by the Ethical Committee at the Faculty of Pharmacy, Cairo University.

\section{Electromagnetic wave (EMW) exposing process}

Animals were exposed to electromagnetic wave using a device that's designed and constructed locally in the Radiation Physics Department, NCRRT, Nasr City, Cairo, Egypt. The device was constructed to study the biological effect between 0.01 and 20 GHz (Gharib et al., 2010). The animals were exposed to microwave $950 \mathrm{MHz}$ at a specific absorption rate $(\mathrm{SAR}=1.6 \mathrm{~W} / \mathrm{Kg})$ for 60 days ( 3 hrs daily during the light period).

\section{Irradiation process}

A single dose whole body irradiation (4 Gy) was performed with rats, using Canadian gamma cell- 40 biological radiator furnished with Cesium 137 source (Atomic Energy of Canada LTD), National Center for Radiation Research and Technology (NCRRT), with the dose rate $0.6797 \mathrm{rad} / \mathrm{Sec}$. The gamma cesium cell was calibrated by alanine dosimetry relative to a primary standard. Correction were made daily for humidity, temperature, and barometric pressure.

\section{Experimental Design}

Rats were segregated into six groups $(n=6)$. Group 1 received saline and served as controls. Group 2 was orally administered with a cumulative dose of Ziziphus (400 mg/ Kg b.wt for 14 consecutive days) diluted in $0.4 \mathrm{ml}$ distilled water. Group 3 was exposed to whole body electromagnetic wave $950 \mathrm{MHz}$ three hours daily for 60 days. Group 4 was exposed to irradiation whole body gamma with a single dose of 4 Gy. Group 5 was exposed to whole body electromagnetic wave $950 \mathrm{MHz}$ three hours 
daily for 60 days followed by ionizing $\gamma$ irradiation (4 Gy). Group 6 was exposed to electromagnetic wave $950 \mathrm{MHz}$ three hours daily for 60 days and they were orally administered with the cumulative dose of $400 \mathrm{mg} / \mathrm{Kg}$ Ziziphus at the last 14 days; at the end of the day 60 , animals were exposed to $4 \mathrm{~Gy}$ single dose of whole body $\gamma$ - irradiation. All animal groups were sacrificed after 48 hours of radiation exposure, blood samples were withdrawn from the retro-orbital venous plexus using non heparinized capillary tubes and liver samples were immediately removed, rinsed with saline to eliminate blood contamination, dried by blotting with filter paper and then divided into two portions for various biochemical and histopathological examinations.

\section{Biochemical Analysis}

Each blood sample was collected into non-heparinized tube. The blood samples were allowed to coagulate and then centrifuged at 3000 r.p.m. for 20 min. The separated sera were used for the estimation of AFP, ALT and AST, while the following parameters were measured in the liver homogenate of the six tested rat groups, according to the instructions of their referred methods.

\section{METHODS}

\section{Assessment of hepatic biochemical markers in serum}

Serum AFP was colorimetrically assayed using the rat AFP ELISA Kit. In addition, serum AST and ALT activities were colorimetrically assayed using test reagent kit according to Huang et al., 2006.

\section{Assessment of hepatic antioxidant and oxidative stress biomarkers}

Liver tissues were homogenized in ice-cold 0.1 $\mathrm{M}$ phosphate buffer saline ( $\mathrm{pH}$ 7.4) for estimation of the activity of Hepatic glutathione peroxidase (GPx) was evaluated according to Prabhu (2002), hepatic lipid peroxides using malondialdehyde (MDA) as an indicator according to the method of Devasagayam (2003). In addition, hepatic nitric oxide (NO) was evaluated according to Baezzat et al. (2011).

Assessment of NFkB, heat shock protein (HSP70) and P53

Hepatic NFkB was determined using rat Nuclear Factor $\kappa \mathrm{B}(\mathrm{NF} \kappa \mathrm{B})$ Elisa kit (Competitive ELISA). Catalog number: MBS722386 for tissue homogenates, Synatom Research,Princeton, New Jersey, United States. Furthermore, gene expressions of HSP70 and P53 were estimated by Quantitative realtime PCR technique.

\section{RNA extraction}

Total RNA was purified from the liver tissues using RN easy Purification Reagent (Qiagen, Valencia, California) according to the manufacturer's protocol. Extracted RNA was quantified by spectrophotometer at 260/280 nm and its integrity was assessed by gel electrophoresis on $1 \%$ agarose gel stained with ethidium bromide. Reverse transcription was carried out on $5 \mu \mathrm{g}$ RNA from each liver sample using MMuLV reverse transcriptase in a $50 \mu \mathrm{L}$ reaction volume. Mixtures of the reverse transcription were used for amplification of fragments specific for liver heat shock protein 70 and P53by PCR using the primer pairs listed below.

\section{Real-time quantitative polymerase chain reaction} (PCR)

Liver heat shock protein and P53 gene expression were measured by means of real time PCR (RTPCR). In brief, first-strand cDNA synthesis was performed with the Super Script Choice System (Life Technologies, Breda, Netherlands) according to the manufacturer's protocol. For quantitative real-time PCR, 5 ul of first-strand cDNA was used in a total volume of $25 \mathrm{ul}$, containing $200 \mathrm{ng}$ of specific primer and 12.5 ul 2x SYBR Green PCR Master Mix.

The primer sequences of heat shock protein (HSP70) as follows: 
Forward; 5-TTCGTGGCTGGAGGTCAATC-3, and Reverse; 5-TAATGATTTGAAGATGAGGGG-3, (Gene bank accession number; NM_005527.3).

The primer sequences for P53 as follows:

Forward; 5'-CGCAAAAGAAGAAGCCACTA-3, and Reverse; 5'-TCCACTCTGGGCATCCTT-3,

The primer sequence for Glyceraldehyde-3-phosphate dehydrogenase (GAPDH) as follows:

Forward: TCATTGACCTGAACTACAT Reverse: GAAGATGGTGATGGACTT

(Gene bank accession number; NM_001087756.1).

PCR reactions consist of 1 cycle at $95^{\circ} \mathrm{C}$ for $10 \mathrm{~min}, 94^{\circ} \mathrm{C}$ for $15 \mathrm{Sec}$ and 40 cycles at $60^{\circ} \mathrm{C}$ for $1 \mathrm{~min}$. These reactions were performed on an ABI Prism 7900 HT Fast Real Time PCR system (Applied Biosystems). The mRNA levels were calculated based on the method of Livak and Schmittgen (2001). Glyceraldehyde-3-phosphate dehydrogenase (GAPDH) (R\&D Systems Inc., USA) was used as a housekeeping gene.

\section{Tissue preparation for histology}

Liver was dissected apart, removed, cut into pieces of approximately $5 \times 5 \times 5 \mathrm{~mm}$. The pieces were immersed in Bouin's solution $(7.5 \mathrm{ml}$ of saturated picric acid, $2.65 \mathrm{ml}$ of glacial acetic acid and $2.5 \mathrm{ml} \mathrm{7 \%}$ formaldehyde) as a fixative for $4 \mathrm{hr}$ at room temperature under continuous gentle gyrotory shaking; the fixative was changed once. The Bouin's fixative was washed from the samples with $70 \%$ ethyl alcohol and fixed cross sections of the liver were embedded in paraffin wax by routine methodology. The paraffin blocks were cut into $5 \mu \mathrm{m}$ thick sections and stained with hematoxylin and eosin (H \& E) (Carson, 1992). All liver sections were examined using light microscope.

\section{Statistical analysis system}

The data were expressed as mean \pm standard deviation (SD) and were analyzed by one- way analysis of variances (ANOVA) followed by Tukey-Kramer multiple comparisons test. Statistical analysis was done by using Graph-Pad software, San Diego, CA, USA. Differences were considered statistically significant when $\mathrm{P}<0.05$.

\section{RESULTS}

\section{Biochemical results}

Table (1) exemplifies the effect of EMW and/ or 4 Gy $\gamma$-radiation exposures on liver biomarker measured as serum AFP level as well as ALT and AST activities. Exposing rats to EMW and/ or irradiation caused a significant rise in serum AFP level as matched to control rats. The increase in AFP, ALT and AST activities were more obvious in the group exposed to double treatment of EMW and $\gamma$-rays (group 5). The percentage differences of AFP, ALT and AST level in group 5 was $168.4 \%, 182 \%$ and $78 \%$, respectively as compared to normal control levels (group 1). Otherwise, the difference between EMW exposure group (group 3) and 4 Gy dose of gamma radiation exposure group (group 4) is nonsignificant in all the previous parameters. Moreover, administration of ziziphus to EMW and irradiated rats (group 6) caused a full restoration showing a non significant change as in all serum biomarkers levels as compared to the control group Table (1).

Table (2) show the effect of EMW and/ or 4 Gy $\gamma$-radiation exposures on both liver antioxidant and oxidative stress bio-markers that measured as the activity of GPx as well as NO and MDA levels, respectively. Treated rats with EMW and/ or 4 Gy $\gamma$-radiation (groups 3, $4 \& 5$ ) revealed a significant decline in liver GPx activity accompanied by a sharp rise in NO and MDA levels as compared to the control group (group 1). The percentage differences of GPx decline were $41.9 \%, 49.4 \%$ and $69.3 \%$, respectively, while the increase recorded in $\mathrm{NO}$ as 69 , 139.5 and $318.7 \%$, respectively, and MDA levels recorded $326.4 \%, 313 \%$ and $578.6 \%$, respectively as compared to group (1), while there is a significant 
difference between EMW exposure group (group 3) and 4 Gy dose of gamma radiation exposure group (group 4) in NO level. The activity of GPx showed a marked fall in the group of animals submitted to the both treatment (EMW and $\gamma$-rays, group 5). On the other hand, the increase was insignificant between EMW and IRR group (group 3 and 4) in case of NO and MDA, while a combined treatment as in group 5 (EMW + IRR) showed a marked increase in liver $\mathrm{NO}$ and MDA levels as compared to control group. Administration of the Ziziphus extract (groups 6) caused a moderate amelioration in GPx (-24\%), NO (74\%) and MDA (123.6\%) levels when compared to normal control level (Table 2).

Table (1): Changes in serum AFP level, ALT and AST activities, in EMW and/ or $\gamma$-radiation exposed rats and the ameliorative role of ethanol ziziphus extract treatment.

\begin{tabular}{|c|c|c|c|c|c|c|}
\hline \multirow{2}{*}{ Parameter } & \multicolumn{5}{|c|}{ Experimental groups } \\
\cline { 2 - 7 } & Group 1 & Group 2 & Group 3 & Group 4 & Group 5 & Group 6 \\
\cline { 2 - 7 } & Control & Z & EMW & IRR & EMW+IRR & $\begin{array}{c}\text { EMW+Z } \\
+ \text { IRR }\end{array}$ \\
\hline AFP (ng/ml) & $0.77 \pm 0.125$ & $0.643 \pm 0.029^{\mathrm{b}}$ & $1.4 \pm 0.089^{\mathrm{a}, \mathrm{b}}$ & $1.45 \pm 0.045^{\mathrm{a}, \mathrm{b}}$ & $2.067 \pm 0.197^{\mathrm{a}}$ & $0.905 \pm 0.031^{\mathrm{b}}$ \\
\hline ALT (U/L) & $16.05 \pm 2.96$ & $17.83 \pm 4.22$ & $23.38 \pm 4.05^{\mathrm{b}}$ & $21.06 \pm 0.86^{\mathrm{b}}$ & $45.29 \pm 10.69^{\mathrm{a}}$ & $24.48 \pm 5.19^{\mathrm{b}}$ \\
\hline AST (U/L) & $44.82 \pm 9.5$ & $39.82 \pm 8.24$ & $64.99 \pm 5.42^{\mathrm{a}}$ & $78.34 \pm 13.66^{\mathrm{a}}$ & $79.82 \pm 10.06^{\mathrm{a}}$ & $46.54 \pm 9.21^{\mathrm{b}}$ \\
\hline
\end{tabular}

Results are expressed as means $\pm S D(n=6)$.

(a) Significantly different from the control group, (b) significant different from (EMW+IRR) treated group at P<0.05. Statistical analysis was held out by one- way ANOVA followed by Tukey-Kramer Multiple Comparison Test.

Table (2) : Changes in liver GPx activity, NO and MDA levels in EMW and/ or $\gamma$-radiation exposed rats and the ameliorative role of ethanol ziziphus extract treatment.

\begin{tabular}{|c|c|c|c|c|c|c|}
\hline \multirow{3}{*}{ Parameter } & \multicolumn{6}{|c|}{ Experimental groups } \\
\hline & Group 1 & Group 2 & Group 3 & Group 4 & Group 5 & Group 6 \\
\hline & Control & $\mathbf{Z}$ & EMW & IRR & EMW+ IRR & $\begin{array}{c}\text { EMW+Z } \\
\text { IRR + }\end{array}$ \\
\hline $\begin{array}{c}\text { GPX } \\
\text { (U/g protein) }\end{array}$ & $84.35 \pm 1.74$ & $83.97 \pm 6.55^{b}$ & $49.03 \pm 1.53^{\mathrm{a}, \mathrm{b}}$ & $42.67 \pm 4.07^{\mathrm{a}, \mathrm{b}}$ & $25.87 \pm 4.15^{\mathrm{a}}$ & $64.05 \pm 6.4^{\mathrm{a}, \mathrm{b}}$ \\
\hline $\begin{array}{c}\mathrm{NO} \\
\mu \mathrm{mol} / \mathrm{g} \text { ) } \\
\text { (protein }\end{array}$ & $11.9 \pm 1.52$ & $11.1 \pm 1.87^{\mathrm{b}}$ & $20.13 \pm 2.95^{\mathrm{a}, \mathrm{b}}$ & $28.5 \pm 2.66^{\mathrm{a}, \mathrm{b}}$ & $49.83 \pm 8.45^{\mathrm{a}}$ & $20.7 \pm 0.89^{\mathrm{a}, \mathrm{b}}$ \\
\hline $\begin{array}{c}\text { MDA } \\
\text { nmol/g) } \\
\text { (protein }\end{array}$ & $1.45 \pm 0.22$ & $1.39 \pm 0.48^{b}$ & $6.183 \pm 5.416^{\mathrm{a}}$ & $5.989 \pm 13.66^{\mathrm{a}}$ & $9.839 \pm 10.06^{\mathrm{a}}$ & $3.242 \pm 9.213^{b}$ \\
\hline
\end{tabular}

Results are expressed as means $\pm S D(n=6)$.

(a) Significantly different from the control group, (b) significantly different from (EMW+IRR) treated group at $P<0.05$

Statistical analysis was carried out by one way ANOVA followed by Tukey-Kramer Multiple Comparison Test. 
Exposing rats with EMW and/ or radiation (groups 3, 4 and 5) shown a highly significant rise in Both liver HSP70 with the percentage difference $198 \%, 292 \%$ and $416 \%$, respectively, and NF- $\kappa B$ with the percentage difference $49.8 \%, 70 \%$ and $103.9 \%$, respectively, that accompanied by a pronounced decrease in P53 with percentage differences 42.6, 63.4 and $50.5 \%$ when compared to control rats group (group 1). Moreover, the difference between EMW exposure group (group 3) and 4 Gy dose of gamma radiation exposure group (group 4) is non-significant in both HSp70 and P53 expression levels. However, rats treated with Ziziphus extract (groups 6) showed a descent in the increase of HSP70 $(32.9 \%, 19 \%$ and $61 \%$, respectively) and NF- $\mathrm{\kappa B}(12.9 \%, 41.9 \%$ and $36 \%$, respectively) levels that induced by EMW and/ or radiation exposure (groups 3, 4\& 5). Moreover, administration of the Ziziphus extract (groups 6) to rats caused a moderate restoration $-17 \%$ in P53 as compared to control group, since Ziziphus treatment was affected obviously on the level of the previous parameters (Table 3).

Table (3) : Changes in liver HSP 7, NFkB and P53 levels in rats exposed to EMW and/ or $\gamma$-radiation and the ameliorative role of ethanol ziziphus extract treatment.

\begin{tabular}{|c|c|c|c|c|c|c|}
\hline \multirow{2}{*}{ Parameter } & \multicolumn{5}{|c|}{ Experimental groups } \\
\cline { 2 - 7 } & Group 1 & Group 2 & Group 3 & Group 4 & Group 5 & Group 6 \\
\cline { 2 - 7 } & Control & $\mathbf{Z}$ & EMW & IRR & EMW+ IRR & $\begin{array}{c}\text { EMW+Z } \\
+ \text { IRR }\end{array}$ \\
\hline HSP 70 & $1.04 \pm 0.046^{\mathrm{b}}$ & $1.01 \pm 0.01^{\mathrm{b}}$ & $3.1 \pm 0.268^{\mathrm{a}, \mathrm{b}}$ & $4.08 \pm 0.319^{\mathrm{a}, \mathrm{b}}$ & $5.37 \pm 1.05^{\mathrm{a}}$ & $2.08 \pm 0.018^{\mathrm{a}, \mathrm{b}}$ \\
\hline $\begin{array}{c}\text { NFkB } \\
\text { nmol/g) } \\
\text { (protein }\end{array}$ & $75.7 \pm 3.9^{\mathrm{b}}$ & $81.43 \pm 5.99^{\mathrm{b}}$ & $113.43 \pm 7.92^{\mathrm{a}, \mathrm{b}}$ & $129.01 \pm 17.48^{\mathrm{a}, \mathrm{b}}$ & $154.33 \pm 10.94^{\mathrm{a}}$ & $98.75 \pm 2.19^{\mathrm{a}, \mathrm{b}}$ \\
\hline \begin{tabular}{c} 
P53 \\
\hline
\end{tabular} & $1.01 \pm 0.015^{\mathrm{b}}$ & $1.003 \pm 0.005^{\mathrm{b}}$ & $0.58 \pm 0.117^{\mathrm{a}, \mathrm{b}}$ & $0.37 \pm 0.187^{\mathrm{a}, \mathrm{b}}$ & $0.197 \pm 0.052^{\mathrm{a}}$ & $0.837 \pm 0.049^{\mathrm{a}, \mathrm{b}}$ \\
\hline
\end{tabular}

Results are expressed as means $\pm S D(n=6)$.

(a) Significantly different from the control group, (b) significant different from (EMW+IRR) treated group at $P<0.05$ Statistical analysis was carried out by one way ANOVA followed by Tukey-Kramer Multiple Comparison Test.

\section{Histopathological results}

The histology of control group slides shows an average central vein with intact epithelial lining, the hepatocytes arranged in single cell cord with average blood sinusoid, portal vein and bile duct (Figure 1). In case of rats exposed to electromagnetic wave with the frequency of $950 \mathrm{MHz}$ or 4 Gy gamma rays; the central vein became dilated with intact epithelial lining and dilated congested blood sinusoids with scattered apoptotic hepatocytes. The portal vein became mildly dilated with mild inflammatory cellular infiltrate in portal tract. Exposure to electromagnetic waves $950 \mathrm{MHz}$ and gamma radiation (4 Gy) showed hepatocyte necrosis, marked inflammatory infiltrate and expanded Portal tracts (Figure 2), meanwhile Figure (3) showed that ziziphus treatment improve this inflammation and protect against hepatocyte necrosis and hepatocytes were arranged in single cell cords, central vein was average in size and has an intact epithelial lining. 


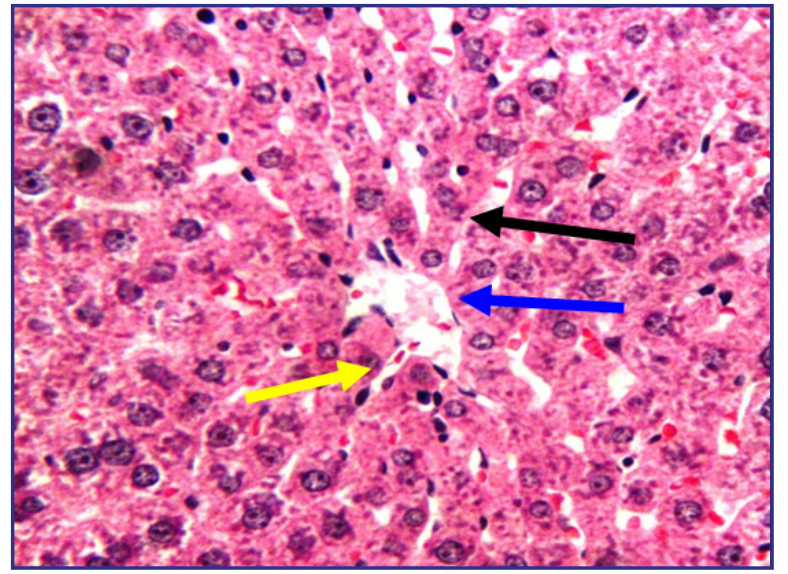

Fig. (1): Group 1 (Control): liver tissue showing average central vein with intact epithelial lining (blue arrow), hepatocytes arranged in single-cell cords (black arrow) with average blood sinusoids (yellow arrow) (H\&E X 400).

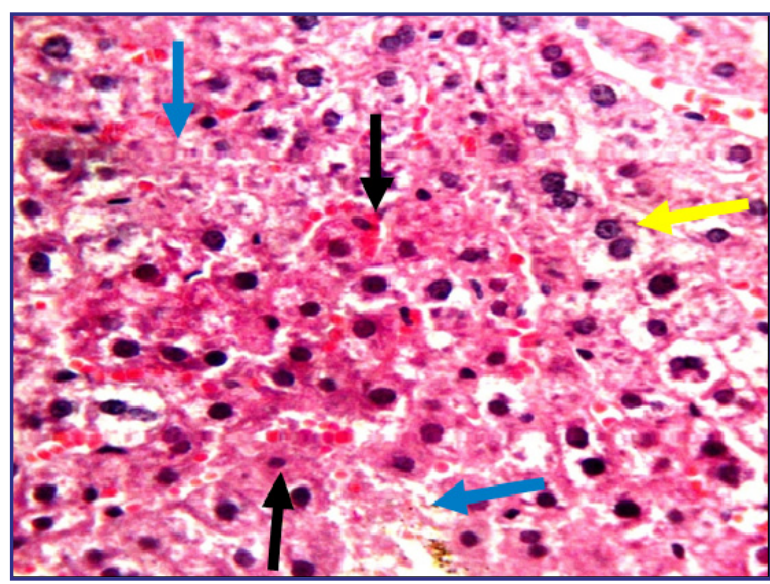

Fig. (2): Group 5 (EMW+ IRR): liver tissues showing areas of necrosis (blue arrows) with apoptotic (black arrows) and bi-nucleated hepatocytes (yellow arrow) (H\&E X 400).

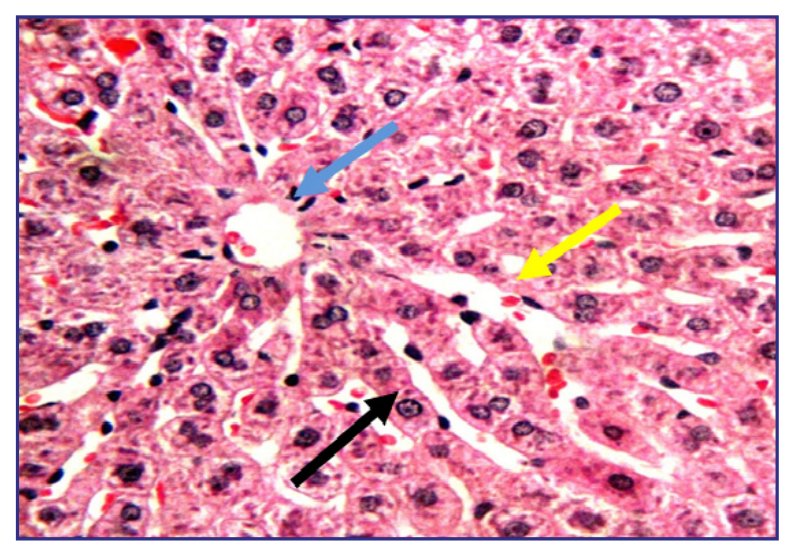

Fig. (3): Group 6 (EMW+ Z+ IRR): liver tissues showing average central vein with intact epithelial liming (blue arrow), hepatocytes arranged in single cell cords (black arrow) with dilated irregular blood sinusoids (yellow arrow) (H\&E X 400).

\section{DISCUSSION}

In this study exposure to EMW had a significant influence on rat liver; confirmed by the intensification in the serum level of AFP, AST and ALT comparing to the control group levels, proposing that ROS were generated under the experimental conditions employed due to the possible effect of EMW and/ or ionizing radiation, which affects the mitochondrial membranes to produce great quantities of oxygen radicals; causing leakage of large quantities of serum enzymes into the blood stream was associated with centrilobular necrosis, ballooning degeneration, and cellular infiltration of liver (Ozguner et al., 2005). Moreover, EMW and/or radiation exposure on rats affected a significant reduction in the natural process of liver GPx with the rise in the NO, MDA and HSP 70 levels as compared to control values. Aforementioned investigators accounted comparable data; they noticed a decrease in the level of GPX with a rise in the level of NO (Ozguner et al., 2005), MDA (Akan et al., 2010) and HSP 70 (Fahmy et al., 2016) in liver tissue, after EMW as well as, $\gamma$-ray exposure. The decrease in the activity of liver GPx could be owing to either free radical dependent inactivation of enzyme or decline of its co- substrates, that is GSH and NADPH (Dahiru and Obidoa, 2008). Accordingly, the capability of liver to scavenge toxic $\mathrm{H}_{2} \mathrm{O}_{2}$ and lipid peroxide was lessened (Akan et al., 2010). Thus, dropped antioxidant status partially explains the mechanism of hepatotoxicity induced by EMW and /or $\gamma$-irradiation. Cellular response to stresses is signified at the molecular level by speedy synthesis of molecular chaperones such as HSP70 (Huang et al., 2001). Through the chaperone role, HSPs are likely to defend proteins against denaturation or oxidative inactivation, or support in the folding of stress-modified proteins (Martindale and Holbrook, 1999). HSP70 and HSP90 chaperones cooperate in client protein folding to an active conformation, protein stabilization, and protein turnover by the creation of multichaperone complexes. The regulation of Hsp90 client proteins is connected 
to the function of Hsp70. It initially tries to buffer the effect of oxidative damage followed by Hsp70depndent protective events (Pratt et al., 2010). Cells have developed mechanisms associated with induction of HSPs to maintain cellular homeostasis and try to cope with the overloading of ROS produced during oxidative stress. The similar results were obtained in the present study. In addition, the rise in NO and MDA levels due to EMW exposure and/ or $\gamma$-irradiation was considered as an index of increased ROS production occurring throughout the exposure period and may reflect the pathological process of the exposure. The increase was suggesting a potential action of EMW in inducing nitric oxide synthase under experimental disorders. In addition, the positive correlation found between NO and MDA levels may propose that $\mathrm{NO}$ behaves as an oxidant radical (Ozguner et al., 2005).

The present study indicated that EMW and/ or radiation exposure of rats produced a significant increase in liver NF- $\mathrm{KB}$ gene expression, which was go together with a decrease in P53 level, that is in agreement with the results recorded by Cacha-o et al., 2010. Alteration in all tested parameters was amplified in rats exposed to EMW and $\gamma$-rays; representing that irradiation strengthens the toxic effect of EMW. Interestingly, these results may be mainly due to the induction of TNF- $\alpha$ after radiation exposure (Klefstrom et al., 1997), The NF-kB family of transcription factors has an essential role in protecting the cells from apoptosis during exposure to a variety of stressors. Under normal condition, NF-kB is present in the cytoplasm in an inactive form by inhibitory $\kappa \mathrm{B}(\mathrm{I} \kappa \mathrm{B})$. Once activated, I $\mathrm{KB}$ is phosphorylated and degraded, which permits NF- $\mathrm{BB}$ p50 to translocate to the nucleus and induce the expression of its target genes upon activation by oxidative stress stimuli, hence resulting in release of pro-inflammatory cytokines, which ultimately leading to hepatic damage (Shih et al., 2015), (Tang et al., 2017). Since exposing to EMW and/ or ionizing radiation exposure lead to excessive ROS production, it activates the transcription factor to modulate the antioxidant system. A few earlier reports demonstrated that an increase in ROS may result in NF-kB activation and other transcription factor such as MAPK which can have important consequences for cell survival and cell signaling (Bowie and O'Neill et al., 2000). In our present results once ROS levels increased after EMW and/ or ionizing radiation exposure it affects the antioxidant status specifically glutathione metabolism that induce an increase in lipid peroxidation. In such situations, HSPs act as the central mediators to regulate the NF-kB activation and translocation process. Moreover, Klefstrom and his colleagues mentioned that P53 and NF- $\kappa$ B may functionally control each other (Klefstrom et al., 1997). In addition, ROS induced by the exposure of EMW and ionizing radiation, are the most common factors that induce NF- $\kappa B$ activation (Xiao et al., 2008). EMW and ionizing radiations activate NF- $\mathrm{NB}$ via the protein kinases ATM or DNA-PK. ATM is a nuclear serine kinase that upon sensing DNA damage stimulates several signaling pathways to modulate the cell cycle, stress and DNA repair (Fahmy et al., 2016). According to Tang and his colleagues' the interaction of Toll like receptor (TLR) 4 and lipopolysaccharide (LPS) result in the stimulation of $N F-\kappa B$ (Kawai and Akira, 2007), which is composed of p50 and p65 subunits (Tang et al., 2017). According to the above results the effect of 4 Gy dose of gamma radiation is more pronounced than that of EMW exposure in some parameters, this may be due to the nature of both types of radiation. Ionizing irradiation is more harmful to human and animals per unit of energy deposited than non-ionizing radiation, as the ions that are developed are excited to combine in semi-random techniques with other particles in the environment and form free radicals (Li et al., 2000). By contrast, most non-ionizing radiation is damaging to organisms only in proportion to the thermal energy deposited and is usually considered harmless at low powers that do not create a considerable temperature increase (Deepinder et al., 2007). 
Based on the results of the current study administration of leaves ziziphus extract improves the toxicity induced by both non-ionizing and ionizing radiation exposure recorded as a decrease in AFP, ALT and AST activities as well as the histological results of liver organ. This decrease may be due to the protection of both plasma membrane and liver cells contrary to membrane damage as a result of radiation toxicity and, by this means, decreasing the leakage of serum enzymes markers into circulation (Dahiru and Obidoa, 2008). According to Hikino and his colleagues' tannins are known to apply antihepatotoxic action (Hikino et al., 1985). The basis for the hepatoprotective action of tannins has been ascribed to the formation of an impervious polyphenol- protein and/ or polysaccharide layer under which the natural healing processes can occur (Yahyapour et al., 2018). An interesting outcome in the present study was the effect of ziziphus extract administration on irradiated rats by both non- ionizing and ionizing radiation induced a significant improvement of HSP 70, NF-kB and P53 levels comparable as the irradiated group of animals. According to Bongiovanni and his colleagues' the dietary supplementation of flavonoids may cause protection against acute HSP (Bongiovanni et al., 2007). Moreover, flavonoids inhibit the expression of HSP70, which in turn modulates the activities of GPx that regulate cellular redox status (Fischer et al., 2018), (Guo et al., 2007). The results suggested the pharmacological possibilities of flavonoids in diseases derived from the abnormal expression of HSP. As well, it was reported that Kaempferol and quercetin; the ones belong to flavonoid found in ziziphus extract (Herbani and Bintari, 2017); inhibited the NF-kB through the suppression of the phosphorylation of IKK and IKKB accompanied with a reduction in nucleus and cytoplasm (Porras et al., 2016) causing a modulation of iNOS (nitric oxide synthase), which play the major role in regulating the high levels of nitric oxide (Rezaeyan et al., 2016). In addition, Najafi et al. demonstrate that the flavonoid could re- duce NO radical production through the preventing the binding of NF-kB to the iNOS promoter (Najafi et al., 2018). The collective evidence suggests that flavonoid interfere with NF-kB activation not only by correcting the changes in the cell redox state, but also by specific binding to proteins tangled in the NFkB (Gomes et al., 2008). Our result further showed that the rats orally treated with ziziphus extract along with non-ionizing and ionizing $\gamma$-irradiation significantly improved the double unfavorable effects. This is obvious by the increase in the level of antioxidant GPx enzyme and the decrease in the level of MDA in liver. Literature survey revealed that polyphenolic compounds have been shown to guard various cell types from oxidative stress mediated cell injury (Sasaki et al., 2002). The phenolic structure of flavonoids partition into the hydrophobic core of the membrane can cause a modification of lipid fluidity (Arti et al., 2000). Flavonoids have been reported to reduce the peroxidation of polyunsaturated fatty acids in cell membranes. These substances, could react with the deeper membrane domains and intracellular structures, and guard the cells from oxidant injury (Kaviaran et al., 2006).

The histological examination of liver tissue in group of animals exposed to EMW and a single dose of gamma rays ionizing radiation showed histopathological changes, which may be owing to the interaction of free radicals with the polyunsaturated fatty acids in phospholipids portion of cell membrane initiating the lipid peroxidation chain reaction (Spitz et al., 2004). Administration in rats with ziziphus extract to the irradiated animals with both EMW and $\gamma$ - rays ionizing radiation showed a significant amelioration in the configuration and architecture of liver tissue that may be attributed to the anti-hepatotoxic action, free radical scavenging and antioxidant agents of ziziphus extracts. Moreover, the improvement in the hepatic tissue structure was confirmed by the biochemical parameter estimated in this study. 


\section{CONCLUSION}

Our present biochemical and histological data demonstrated clearly that exposing animals to nonionizing or ionizing radiation caused hazard effects due to thermal and free radical action. In addition to the synergistic effects which became more obvious in case of animals exposed to both types of radiation. On the other hand, ziziphus extract, with its anti-hepatotoxic action, free radical scavenging and antioxidant properties, appears to be encouraging agent in guarding the hepatic tissue against EMW with a frequency of $950 \mathrm{MHz}$ and a single dose of gamma rays ionizing radiation (4 Gy) exposures induced oxidative damages. Further study should be done on this plant to formulate it as an antioxidant drug for treatment of hazards induced due to mobile phone and ionizing radiation exposure.

\section{ACKNOWLEDGEMENT}

The authors are appreciated to Dr. Noheir Sherif, Assistant professor of Phytocognosy (NCRRT) for his cooperation in preparing Ziziphus extract.

\section{REFERENCES}

- Akan, Z.; Aksu, B.; Tulunay, A.; Bilsel, S. and Inhan-Garip, A. (2010): Extremely low - frequency electromagnetic fields affect the Immune response of monocyte_derived macrophages to pathogens. Bioelectromagnetics, 31: 603.

- Arti, A.; Byren, T.M. and Nair, M.G. (2000): Modulation of liposomal membrane fluidity by flavonoids. Arch. Biochem. Biophys., 373: 102.

- Baezzat, M.R.; Parsaeian, G. and Zare, M.A. (2011): Determination of traces of nitrate in water samples using spectrophotometric method after its preconcentration on microcrystalline naphthalene. Quim Nova., 34(4): 607.

- Bongiovanni, G.A.; Soria, E.A. and Eynard, A.R. (2007): Effects of the plant flavonoids silymarin and quercetin on arseniteinduced oxidative stress in CHO-K1 cells. Food Chem. Toxico., 145: 971.
- Bowie, A. and O'Neill, L.A. (2000): Oxidative stress and nuclear factor- $\mathrm{\kappa B}$ activation: a reassessment of the evidence in the light of recent discoveries. Biochem. Pharmacol., 59: 13.

- Cachaço, A.S.; Carvalho, T.; Santos, A.C.; Igreja, C.; Fragoso, R.; Osório, C.; Ferreira, M.; Serpa, J.; Correia, S. and Dias, S. (2010): TNF- $\alpha$ regulates the effects of irradiation in the mouse bone marrow microenvironment. PloS one, 5(2): p.e8980.

- Carson, F. (1992): Histotechnology: A self- Instructional Text, $1^{\text {st }} \mathrm{ED}, A S C P ., 19$.

- Dahiru, D. and Obidoa, O. (2008): Evaluation of the antioxidant effects of Ziziphus mauritiana Lam leaf extract against chronic ethanol- induced hepatotoxicity in rat liver. Afr. J. Tradit. Complement Altern. Med. 5(1): 39 .

- Dahiru, D.; Sini, J.M. and John- Africa, L. (2006): Antidiarrhoeal activity of Ziziphus mauritiana root extract in rodents. Afr. J. Biotechnol., 5(10): 941.

- Deepinder, F.; Makker, K. and Agarwal, A. (2007): Cell phones and male infertility: dissecting the relationship. Reprod. Biomed. Online, 15: 266.

- Desai, N.R.; Kesari, K.K. and Agarwal, A. (2009): Pathophysiology of cell phone radiation: oxidative stress and carcinogenesis with focus on male reproductive system. Reprod. Biol. Endocrinol., 22(7): 114.

- Devasagayam, T.P.; Boloor, K.K. and Ramasarma, T. (2003): Methods for estimating lipid peroxidation: An analysis of merits and demerits. India J. Biochem. Biophy., 300: 308.

- Fahmy, H.A.; Abd El Azim, A.S. and Gharib, O.A. (2016): Protective Effects of $\omega-3$ fatty acids and/ or Nano- selenium on Cisplatin and Ionizing radiation induced liver toxicity in rats. Ind. J. Pharmaceut. Edu. Res., 50(4): 649.

- Fischer, N.; Seo, E.J. and Efferth, T. (2018): Prevention from radiation damage by natural products. Phytomedicine., 47: 192. 
- Gharib, O.A. and Ibrahim, N.K. (2010): Oxidative damage in testes induced by $950 \mathrm{MHz}$ simulating cellular phone. Isotope \& Rad. Res., 42(4): 941.

- Ghodbane, S.; Lahbib, A.; Sakly, M. and Abdelmelek, H. (2013): Bioeffects of static magnetic fields: oxidative stress, genotoxic effects, and cancer studies. Biomed. Res. Int., 2013: 60287.

- Gomes, A.; Fernandes, E.; Lima, J.L.; Mira, L. and Corvo, M.L. (2008): Molecular mechanisms of anti inflammatory activity mediated by flavonoids. Curr. Med. Chem., 15: 1586.

- Guo, S.; Wharton, W.; Moseley, P. and Shi, H. (2007): Heat shock protein 70 regulates cellular redox status by modulating glutathione-related enzyme activities. Cell Stress Chaperones. Autumn., 12(3): 245 .

- Hassan, S.B.; Gali-Muhtasib, H.; Göransson, H. and Larsson, R. (2010): Alpha terpineol: a potential anticancer agent which acts through suppressing NFkappaB signalling. Anticancer Res., 30(6): 1911.

- Herbani, M. and Bintari, Y.R. (2017): In silico studies on Bidara (Ziziphus mauritiana) leaves ethanol extract bioactive ligands compared to Acarbose towards $\alpha$-glucosidase enzymes. JIMR., 1(2):1-9.

- Hikino, H.; Kiso, V. Hatano, T. Yoshida, T. and Okuda, T. (1985): Antihepatotoxic action of tannins. J. Ethnopharmacol., 14: 19.

- Huang, L.; Mivechi, N.F. and Moskophidis, D. (2001): Insights into regulation and function of the major stress-induced hsp70 molecular chaperone in vivo: analysis of mice with targeted gene disruption of the hsp70.1 or hsp70.3 gene. Mol. Cell. Biol., 21(24): 8575.

- Huang, X.J.; Choi, Y.K.; Im, H.S.; Yarimaga, O.; Yoon, E. and Kim, H.S. (2006): Aspartate aminotransferase (AST/GOT) and alanine aminotransferase (ALT/GPT) detection techniques. Sensors, 6(7): 756.

- Ikram, M. and Tomlinson, H. (1976): Chemical constituents of Zizyphus spina christi. Planta Med., 29(3): 289 .
- Kaviaran, S.; Ramamurty, N.; Gunasekaran, P.; Varalakshmi, E. and Anuradha, C.V. (2006): Fenugreek (Trigonella Forum graecum) seed extract prevents ethanol induced toxicity and apoptosis in change liver cells. Alc. Alcohol., 41(3): 267.

- Kawai, T. and Akira, S. (2007): Signaling to nf-kappab by toll-like receptors. Trends Mol. Med., 13: 460.

- Kil, H.Y.; Seong, E.S.; Ghimire, B.K.; Chung, I.M.; Kwon, S.S.; Goh, E.J.; Heo, K.; Kim, M.J.; Lim, J.D.; Lee, D. and Yu, C.Y. (2009): Antioxidant and antimicrobial activities of crude sorghum extract. Food Chem., 115: 1234.

- Klefstrom, J.; Arighi, E.; Littlewood, T.; Jäättelä, M.; Saksela, E.; Evan, G.I. and Alitalo, K. (1997): Induction of TNF-sensitive cellular phenotype by cMyc involves p53 and impaired NF- $\kappa \mathrm{B}$ activation. EMBO J., 16(24): 7382.

- LaVerne, J.A. (2000): $\mathrm{OH}$ radicals and oxidizing products in the gamma radiolysis of water. Rad. Res., 153(2): 196 .

- $\quad$ Li, J.S.; Pawliki, T.; Deng, J.; Jiang, S.B.; Mok, E. and Ma, C.M. (2000): Validation of a monte carlo dose calculation tool for radiotherapy treatment planning. Phys. Med. Biol., 45: 2968-85.

- LivaK, K. and Schmittgen, T. (2001): Analysis of relative gene expression data using real-time quantitative PCR and the 2 (-Delta Delta C (T)) method. Methods., 25: 402.

- Martindale, J.L. and Holbrook, N.J. (2002): Cellular response to oxidative stress: signaling for suicide and survival. J. Cell Physiol., 192: 1.

- Mishra, A.; Kumar, S. and Pandey, A.K. (2013): Scientific validation of the medicinal efficacy of Tinosporacordifolia. The Scientific World Journal. ID 292934.

- Morton, J.F. and Dowling, C.F. (1987): Fruits of warm climates Morton JF (ed), Miami, Florida., 272.

- Najafi, M.; Motevaseli, E.; Shirazi, A.; Geraily, G.; Rezaeyan, A.; Norouzi, F.; Rezapoor, S. and Abdollahi, H. (2018): Mechanisms of inflammatory re- 
sponses to radiation and normal tissues toxicity: clinical implications. Int. J. Rad. Biol., 94(4): 335.

- Ozguner, F.; Oktem, F.; Ayata, A.; Koyu, A. and Ramazan, Y.H. (2005): Novel antioxidant agent caffeic acid phenethyl ester prevents long-term mobile phone exposure-induced renal impairment in rat. Mol. Cell Biochem., 277: 73

- $\quad$ Porras, D.; Nistal, E.; Martínez-Flórez, S.; Pisonero-Vaquero, S.; Olcoz, J.L.; Jover, R.; GonzálezGallego, J.; García-Mediavilla, M.V. and SánchezCampos, S. (2016): Protective effect of quercetin on high-fat diet-induced non-alcoholic fatty liver disease in mice is mediated by modulating intestinal microbiota imbalance and related gut-liver axis activation. Free Radic. Biol. Med., 102: 188.

- Prabhu, H.R. (2002): In vivo inhibition of selenium dependent glutathione peroxidase and superoxide dismutase in rats by diethylthiocarbamate. India J. Exp Bio., 40: 258.

- Pratt, W.B.; Morishima, Y.; Peng, H.M. and Osawa Y. (2010): Proposal for a role of the Hsp90/ Hsp70-based chaperone machinery in making triage decisions when proteins undergo oxidative and toxic damage. Exp. Biol. Med., 235: 278.

- Rezaeyan, A.; Fardid, R.; Haddadi, G.H.; Takhshid, M.A.; Hosseinzadeh, M.; Najafi, M. and Salajegheh, A. (2016): Evaluating radioprotective effect of hesperidin on acute radiation damage in the lung tissue of rats. J. Biomed. Physic. Engin., 6(3): 165 .

- $\quad$ Sasaki, N.; Toda, T.; Kaneko, T.; Baba, N. and Matsuo, M. (2002): Flavonoids suppress the cytotoxicity of linoleic acid hydroperoxide toward PC12 cells. Biol. Pharm. Bull., 25: 1093.

- Shckorbatov, Y. (2014): The Main Approaches of Studying the Mechanisms of Action of Artificial Electromagnetic Fields on Cell. J. Electr. Electron Syst., 3: 2 .

- Shih, R.H.; Wang, C.Y. and Yang, C.M. (2015): NF-kappaB signaling pathways in neurological inflammation: a mini review. Front Mol. Neurosci., 77.
- Spitz, D.R.; Azzam, E.I. and Gius, D. (2004): Metabolic oxidation/reduction reactions and cellular responses to ionizing radiation: a unifying concept in stress response biology. Cancer Metastasis Rev., 23: 311.

- $\quad$ Tang, X.; Wei, R.; Deng, A. and Lei, T. (2017): Protective Effects of Ethanolic Extracts from Artichoke, an Edible Herbal Medicine, against Acute AlcoholInduced Liver Injury in Mice. Nutrients., 9: 1000.

- WHO /IUCN/ WWF. (1993): Guidelines on the Conservation of Medicinal Plants. IUCN, Gland, Switzerland.

- Xiao, C.; Jia, L.i. and Zhuo, L. (2008): Nuclear factor- $\kappa \mathrm{B}$ as a hormonal intracellular signaling molecule: focus on angiotensin II-induced cardiovascular and renal injury. Curr. Opin. Nephrol. Hypertens., 17(1): 37 .

- Yahyapour, R.; Shabeeb, D.; Cheki, M.; Musa, A.E.; Farhood, B.; Rezaeyan, A.; Amini, P.; Fallah, H. and Najafi, M. (2018): Radiation protection and mitigation by natural antioxidants and flavonoids: Implication to radiotherapy and radiation disasters. Curr. Mol. Pharmacol., 4: 285.

- Younes, M.E.; Amer, M.S. and El-Messallami, A.D.E. (1996). Phytochemical examination of the leaves of the Egyptian Ziziphus spina christi - Nabc. Bull. Natio. Re.s Cent., Cairo., 21(1): 35. 
